\title{
Youth media repertoires: Age ranges, context factors and privacy management
}

\author{
Jeffrey Wimmer \\ University of Augsburg - jeffrey.wimmer@phil.uni-augsburg.de \\ Antonia Wurm \\ University of Augsburg - antonia.wurm@student.uni-augsburg.de
}

\begin{abstract}
The overall aim of the study is to trace the interaction between the composition of the media repertoire and the everyday world of adolescents, also looking at privacy management in the course of acquiring digital communication media as part of the media repertoire. In order to do justice to this complexity, young people were not considered as a uniform demographic group, but were divided into three

sive process is to be worked out that makes it possible to also include contextual influencing factors such as peer group, family environment etc. and to expand previous findings on the media repertoire of young people. As a result of this approach, a multi-stage development process was elaborated as well as the privacy management of digital communication media of young people.
\end{abstract} stages. Through this differentiation, a recur-

Keywords: appropiation, media repertoire, social media, youth.

\section{Repertórios de media juvenil: Faixas etárias, fatores de contexto e gestão da privacidade}

\section{Resumo}

O objetivo geral do estudo é traçar a interação entre a composição do repertório mediático e o quotidiano dos adolescentes, considerando também a gestão da privacidade no processo de aquisição dos meios de comunicação digital como parte do repertório mediático. Para fazer jus a essa complexidade, os jovens não foram considerados um grupo demográfico uniforme, mas foram divididos em três estágios. Por meio dessa diferenciação, um processo recursivo deve ser trabalhado que possibilite incluir também fatores de influência contextual, como grupo de pares, ambiente familiar etc. e expandir as descobertas anteriores sobre o repertório dos media dos jovens. Como resultado desta abordagem, foi elaborado um processo de desenvolvimento em várias etapas, bem como a gestão da privacidade dos meios de comunicação digital de jovens.

Palavras-chave: apropriação, juventude, media social, repertório dos media.

(c) The Author(s) 2021. Open access article published online by Interações: Sociedade e as Novas

94 Modernidades, ISSN: 2184-3929, at https://interacoes-ismt.com, under the terms of the Creative Commons Attribution-NonCommercial 4.0 International Licence (https://creativecommons.org/ licenses/by-nc/4.0). 


\section{INTRODUCTION}

Research into the media repertoires of young people often focuses on a descriptive approach, emphasizing the platform and media choices of adolescents. As a result, there is at present a lack of research acknowledging contextual factors of adolescents' everyday world which are crucial for the composition of media repertoire choices. For this reason, the overarching aim of the study was to trace interactions between the composition of the media repertoire and the everyday world of adolescents, including an examination of privacy management in the course of acquiring digital communication media as part of the media repertoire. The focus was on the developmental process of young people between the ages of 13 and 18. A unique feature of this period of life is the individual's profound development process, which takes place within a relatively short period of time. During this time, individual needs, but also self-image and the social environment are subject to constant change (Smetana, Campione-Barr, \& Metzger, 2006; Steinberg, 2014). In order to take account of this complexity, young people were considered not as a uniform demographic group but were instead divided into three stages. This differentiation facilitates the development of a recursive process that allows for the inclusion of relevant contextual factors, such as peer group, family environment, etc. and as a result expands previous findings on the media repertoire of young people. Quantitative studies refer primarily to a descriptive inventory of the media-related actions of young people or were dedicated to specific areas within the media repertoire, such as social media use (e.g., van Kruistum, Leseman, \& de Haan, 2014; York \& Scholl, 2015; Len Rìos et al., 2016). Therefore, the research questions in this study qualitatively explore both media repertoire and indicators of individual usage. This approach allowed for the elaboration of a multi-stage development process, offering new connections for further research.

\section{CONCEPTUAL FRAMEWORK}

\subsection{Media repertoire: Theoretical background}

To begin with, why is it necessary specifically to look into adolescent's media use in the first place? As research demonstrates, adolescence is a crucial period in an individual's life, marking a self and other-oriented development of underlying skills, 
that are "vital for becoming a contributing member of society and with healthy intergroup relations" (Crone \& Fuligni, 2019, p. 447). Closely observing this development not only provides an opportunity to catch a glimpse of what our society is about to become, it also represents an important key for research fields like media literacy and educational sciences. Hence, exploring the media choices of young people is a topic of ongoing relevance and complexity, or as Steinberg puts it briefly "Adolescence is a confusing time, but it's not the people in the midst of it, who are confused" (Steinberg, 2014, p. 1).

Thus far, various different frameworks have been used to study the media repertoire choices of adolescents. A popular approach is a person-centred perspective, which refers to individual preferences and needs that are specifically satisfied by the choice of media set. Examples of this would be the uses and gratification theory (e.g., Katz et al., 1974; Rosengren, Wenner, \& Palmgreen, 1985) or mood management theory (Zillmann, 2000). However, both assume that media users consciously and rationally reflect on their choice of media repertoire at any given time in order to fulfil their needs or influence their mood. Other approaches focus on the structural context as an influencer, emphasizing factors such as availability and cost (Webster, 2011). There are also approaches that attempt to combine both motivational and structural determinants, or quantitative with qualitative research (e.g., Wonneberger et al., 2011; Hasebrink \& Domeyer, 2012). However, integrative constructs like Wonneberger's also refer to specific aspects of the media set, for example news reception. They take up the notion of the duality of media (Webster, 2011), which describes a recursive process between media users and contextual structures, or as Kim summarises:

Media users (i.e., agents) enact their preferences and gratify their media use motivations using resources surrounding them (i.e., structures), whereas the process of media choice is also constrained by various media structures such as infrastructures of media environments. (2014, p.3)

However, this analytical perspective focusses only on media-related action. Hasebrink and Popp (2006) go beyond these direct connections and link the descriptive recording of behavioural patterns of media use and media contact with the context of subjective meaning. Following this idea, the study set itself the goal of also considering contexts that are beyond directly media-related action, but which nevertheless 
influence it in a structuring way. Thus, the development of the media repertoire of young people is to be treated as a recursive process in which the everyday world of young people contains important contextual factors. According to Schütz and Luckmann, the everyday world is, in turn, understood as the area of reality "in which people participate in inescapable, regular recurrence. The everyday lifeworld is the region of reality in which man can intervene and which he can change"1 (Schütz \& Luckmann, 1979, p. 25).

\subsection{Media repertoire: Measurement}

Hasebrink and Domeyer point to a scientific differentiation in media repertoire research between behaviourist approaches such as the uses and gratification theory and media use as "meaningful practice" (2012, p. 759). Following this idea, the interviews were analysed in an attempt to bridge this gap and to depict the interaction between the social context of the media-related action and personal needs. The social context represents media usage as a meaningful practice, while acknowledging personal needs follows uses and gratifications theory, according to which media are used specifically to fulfil individual needs. The social context was divided into three subcategories: Family environment, peer group and school environment. The family environment includes the immediate family circle, the "core family" (Ecarius, Köbel, \& Wahl, 2011, p. 14) to which the respondents feel they belong as a household: An environment in which a special and unique role structure prevails, which is distinguished from the peer group by a special relationship of solidarity and cooperation (Nave-Herz, 2002). The peer group in turn describes unrelated peers who exert great social influence on the individual (Ryan, 2001). The peer group is usually strongly influenced by the individual educational path of adolescents, since, as the interviews showed, the majority of the adolescents' peer group is made up of peers who share the interviewee's school routine or leisure activities. For this reason, academic environment was also included in the social context. This is not only because young people spend a lot of time at school, but also because teachers can also influence media use patterns.

Personal needs represented the behaviourist determinant and was divided into three subcategories: Entertainment, information and participation. Entertainment describes "media offerings that people use primarily because they expect pleasure 1 Own translation. 
or diversion from them" (Rothmund et al., 2015). Information encompasses the way in which young people inform themselves. This includes informing themselves by means of news about current world events as well as about other topics of personal interest. Participation describes both private communication with the peer group, the family or institutions such as school, but also public communication in social media and app applications through which personal information is shared with more than one other person at the same time.

The media repertoire itself is defined here according to Webster and Phalen and describes media use patterns of individuals that last over time (1997), whereby this term stands for both media exposure, such as television, and concrete media actions, such as playing computer games. Consequently, the media repertoire comprises the overall pattern of daily media contacts and daily media use (Hasebrink \& Popp, 2006). Both the social environment and personal needs are seen as variable factors that inherently change over the course of adolescence and thereby influence each other. This, in turn, influences the development of the media repertoire, which also interacts with the social context and personal needs.

\subsection{Privacy management within the media repertoire}

A number of very interesting statements concerning the use of digital communication media as part of the media repertoire emerged during the study. In response, this aspect was specifically addressed. Young people are generally considered to be less aware and reflective about the management of private information on social networks, despite the fact that this has been shown to be a myth (Van Der Velden \& El Emam, 2012: Madden et al., 2013; Marwick \& boyd, 2014; De Wolf, 2020). In fact, young people are quite capable of consciously controlling what content they want to share and with whom, and when. Marwick and boyd summarise it as follows: "Teenagers attempt to simultaneously participate in the networked publics that are foundational to their peer groups while maintaining a degree of privacy. Simply put, they are trying to be in public without always being public" (2014, p. 1052). The use of social media is an important part of young people's everyday media life (Feierabend, Plankenhorn, \& Rathgeb, 2016). For this reason, in addition to the question of which digital communication media young people acquire, the extent to which a management of personal information takes place, how this develops in the period of adolescence and which patterns emerge were also relevant for the evaluation of the 
interviews. By surveying adolescents aged 13 to 18 , the sample included both interviewees who had only recently started using social media and those who had already been active in social networks for several years. Most scientific approaches dealing with privacy management in the digital context refer to the communication privacy management theory (CMP) by Sandra Petronio (2002). This comprises the elements of privacy ownership, privacy control and privacy turbulence (Petronio, 2013). It assumes that individuals see themselves as the sole owners of private information about themselves and are therefore able to control its disclosure. Petronio summarises this as privacy control $(2013$, p. 9). When individuals choose to share information with others, they become "co-owners" (Petronio, 2013, p. 10). In order to control the flow of information shared with co-owners, individuals adopt rules depending on certain factors such as motivation, cultural background, etc. Despite these measures, private information can escape one's control and become accessible to unauthorised co-owners. Petronio describes this as "privacy turbulence" (p. 11). Recent research, which specifically addresses CPM in the context of young people's social media use, finds a kind of "privacy fatigue" (Choi, 2018), in which privacy turbulences are consciously accepted rather than purposefully avoided. De Wolf speaks of a "networked defeatism" that occurs as adolescence progresses, referring to a fatalistic attitude as regards the loss of control of private information (2020, p. 1059). De Wolf suggests that privacy management in social media should be understood as a negotiation process that is influenced by the context of the social environment, the content and the structures of the social networks: "Privacy is not fixed, nor achieved; rather, it should be seen as a process that is dependent on others and on the context wherein one is active" (2020, p. 1059). Building on quantitative research, he concludes that there is a positive correlation between the age of teenagers and the conscious use of privacy management strategies (De Wolf, 2020, p. 1071). Whether or to what extent this developmental process exists among teenagers will therefore also be traced in the following.

\section{RESEARCH DESIGN}

The study was designed as a qualitative interview study. An interview guide was developed that asked questions about daily routine, everyday communication, entertainment, information and participation. Participants were recruited as a convenience sample in the context of a research seminar, where students were asked to 
recruit interviewees from their social networks (Misoch, 2019, p. 207). A total of 47 interviews were conducted in Germany in summer 2019. The gender ratio was relatively balanced, with 25 female and 22 male participants. The interviewees were between 13 and 18 years old at the time of the interview. The largest group was made up of 17- to 18-year-olds with 22 persons; 13 were aged 15 to 16 and 12 persons were between 14 and 13 years old. To track the development of the media repertoire, the sample was divided into three age groups for the evaluation (cf. Table 1 in the appendix). The interviewees were aged 13 to a maximum of 18 years old at the time of their interview. Consequently, this resulted in a sample of boys and girls who had recently reached their teenage years or who were close to the borderline of their twenties. The first stage was therefore defined as the Early Teens group: Early Teens refers to respondents who were 13 to 14 years old at the time of the interview and thus still in their Early Teens. The second stage describes the Middle Teens with an age of 15 to 16 years. The last stage comprises teenagers aged 17 to 18 . Since parts of this group had already reached the age of legal majority and some of them no longer permanently lived in the parental home, they were called Late Teens.

In the interests of ensuring a context-sensitive recording of the everyday worlds of young people, the interviews were coded using the logic of grounded theory (Strübing, 2014; Linke \& Schlote, 2018). In this way, starting from individual conversations, the aim is to abstract a larger picture that allows for a theoretical generalisability of the development of young people's media repertoires (Krotz, 2019). Axial coding made it possible to reconstruct the consolidation of the media set based on six categories (cf. Table 3 in the appendix), as well as to establish theses regarding the dimensions and context specifics investigated (Müller, 2018), which related to the use of media for entertainment, participation and information, as well as to the development of the media repertoire as a whole and the negotiation of privacy management strategies (cf. Table 4 in the appendix).

\section{RESULTS}

\subsection{Early Teens - 13 to 14 years old}

\subsubsection{Entertainment}

Early Teens already use media very confidently and purposefully to entertain themselves and pass the time when they are bored. They often use streaming plat- 
forms such as YouTube, where they can find content on various topics and it is accessible free of charge. Early Teens are also very familiar with pure entertainment media such as computer or console games. The peer group plays an important role in the specific selection of entertainment media. Entertainment media, for example video games, are often consumed together with peers. Furthermore, entertainment media that are not consumed together but alone (for example YouTube videos) are also the basis for conversation and fulfil an important function as follow-up communication. This is evident in the conversation with 13-year-old Manuel:

So, when I go home from school with my friends Sebi and Jan, we tend to talk about personal things, what I've experienced or something funny. Because Jan wouldn't be able to join in because he - well, he very rarely plays Minecraft. But when I go home alone with Sebi, we talk about mobile phone stuff. Minecraft and stuff like that. (Manuel)

In the entertainment category, in general there media use patterns are very consolidated with content that is consciously selected and strongly influenced by the peer group. Of course, a reciprocal influence can be identified, as the choice of peer group is also based on shared personal interests.

\subsubsection{Information}

Information about current world events is only rarely sought out on a teenager's own initiative. In contrast to the entertainment category, where the young people already act very independently, reception in this area is rather more passive. Additionally, the family environment plays a greater role than the peer group. For the most part, Early Teens inform themselves via information media that their parents receive and are thus also accessible to the rest of the household. This can be print media or the radio, for example. Often, these information media are consumed at the same time as the family, for example when parents watch the daily news or sports shows on TV. The extent to which Early Teens are informed about daily news therefore depends largely on both the parents' media repertoire and the accessibility thereof. Parents also play a much greater role than the peer group in assessing the validity of information. When it comes to assessing the trustworthiness, but also the relevance of news, Early Teens trust their parents and circle of friends the most, as was shown in the interviews. When asked why she trusted her parents the most, Olga, 13, replied 
Before they tell me the information [...] they know it's really true. How should I say this? So, before you tell me, you really know if it's true. They don't just tell me because a friend told them, but because they really know what happened. (Olga)

At the same time, not only the media repertoire of the parents, but also the academic environment and the peer group play a role in the question of which topics young people inform themselves about, or are informed about. For example, 13-yearold Ben cites his friends and school as important sources of news.

Well, you hear quite a lot from friends. Or ethics lessons, we talk about terrorism there. And there's a friend of mine who knows everything. I think he watches the news twenty-four hours a day, it's incredible, he really knows everything. (Ben)

The information category, however, does not only describe current events, but also knowledge that the young people need to acquire in the school context. When searching for information independently, they rely on sources of knowledge that are usually found by using search engines. The highest priority here is easy accessibility, which is why the sources themselves are questioned less. As 13-year-old Leonard remarks in the interview.

Question: When you prepare a presentation, for example, what sites do you visit? L: Mostly Wikipedia and Google. But many things are wrong there.

Q: And do you think you can distinguish well between what is true and what is not?

L: Nah, not really. (laughs)

In the area of information, one can therefore speak less of a habitualised media repertoire, which is often fulfilled passively and strongly influenced by the peer group, the media repertoire of the parents and the academic environment.

\subsubsection{Participation}

For daily participation, the use of messengers and social networks still plays a rather subordinate role among Early Teens. Messenger apps are used purposefully 
and expediently to organise everyday life. In this age group, both the peer group and the family exert a great influence on the composition of the media set. For example, parents in this age group have the authority to prohibit or regulate the use of certain media, as was shown, among other things, in the conversation with 13-year-old Leonard.

Q: You don't have Facebook, so I guess you don't have Instagram or anything, do you?

L: Nah, I'm not allowed to.

Q: Why not?

L: My parents say I mustn't use it until I'm sixteen.

Q: Okay and what do you think about that?

L: Actually, all my friends already have Instagram, and I just don't have it: That's rather stupid.

At the same time, the peer group is a decisive factor for the question of which media are suitable for communication. Early Teens are still undergoing a negotiation process in which the technical equipment and the applications used by the peer environment differ greatly. Consequently, Early Teens take their cues from their peers and adapt their media repertoire if necessary. This was also evident in the case of Ben, 13.

B: And a few boys from my class, they're only just getting Snapchat.

Q: Why are they so late?

B: Well, because they all used WhatsApp before. And they started to dislike it too and that's why they're all switching to Snapchat now.

Q: And why do you find Snapchat so much better than WhatsApp, for example?

B: I used to use WhatsApp quite a lot. You see when someone is online, you forget to answer them and then they bug you for half an hour about why you haven't answered.

It also became clear in the interviews that in the Early Teens group, respondents do use social networks or apps to share private information (for example Snapchat or Instagram), but rarely use them to share information about themselves with more than one other person at the same time. Messengers such as WhatsApp are used to organise real-life meetings rather than replace them. In fact, for a face-to-face con- 
versation, written communication via smartphone is perceived as disadvantageous. 14-year-old Larissa describes the advantage of face-to-face communication as follows: "You say, 'what you want to do' and the other person says, 'yes' or 'no'. You don't discuss it so much. With a mobile phone, I think you discuss way more often!" (Larissa). Snapchat, for example, is also used more for one-to-one communication rather than to show snippets of personal life events. The fact that there is already an awareness of privacy management, but that it is not yet more precisely defined, is evident, for example, in the way 14-year-old Larissa formulates it: "Not everyone has to know, so [...] what pictures I take. I don't know" (Larissa) or the interviewee Olga: "No idea, so [...] not everyone has to know what I do during the day, not everyone is interested". These findings partly mirror the findings of De Wolf (2020) that conscious privacy management correlates positively with the age of adolescents. In this case, one can rather speak of an avoidance strategy, in which privacy turbulences are circumvented by sharing little to no private information with more than one other person digitally.

The Early Teens group placed a lot of emphasis on not initiating friendships or acquaintances digitally. Following Petronio's theory (2013), privacy turbulence is more likely to be avoided in this way, as non-digital communication allows people better to be assessed. In this way, it is easier to control which people become co-owners of personal information. The interviewee Olga describes this process as follows.

I just don't like it when I meet a friend through Facebook, for example. So, I want to get to know her in person at the beginning [...] I just think that's better! If I know her personally, I know what she's like. Whether she's nice or whether she's, for example [...] cheeky or whatever. But when she writes with me, she doesn't show that. (Olga)

Overall, it can be summarised that the group of Early Teens does communicate digitally, but more for practical and organisational reasons. Digital contact is seen more as an extension of the non-digital sphere, which can neither replace the beginning of a friendship nor its maintenance in the long run. The main focus of media use among Early Teens tends to lie in the entertainment category. Information tends to be received passively through the media repertoire of parents. Parents and school are important reference instances with regard to the trustworthiness of information. 


\subsection{Middle Teens - 15 to 16 years old}

\subsubsection{Entertainment}

Middle Teens, like Early Teens, use media very intentionally to entertain themselves. A lot of entertainment content is received via streaming platforms such as YouTube, but more often also on paid portals such as Netflix and Amazon prime. The Middle Teens appreciate the constant availability and individualization options that are missing, for example, with standard TV channels. The peer group also plays a major role in the choice of entertainment media among Middle Teens, as they often have the same interests or the received content is the basis for conversation. In a conversation about 15-year-old Jonas' favourite YouTube users, he puts it as follows.

Because it's funny and for entertainment. Yes, I have a friend who also likes to watch it and then we can talk about it. I just think the guy himself is brilliant, what he has achieved and how he continues to do it. (Jonas)

But the possibility of individualization is also becoming increasingly important, which is why YouTube or Netflix, for example, are preferred over television. Overall, it became apparent that the spectrum of entertainment media used by Middle Teens is diversifying, but access restrictions (e.g., costs) and the peer group continue to play an important role. For example, 16-year-old Nina answered the question why she does not use Netflix.

Because my parents have Prime and I have the password for it (laughter). So, my sister has a Netflix account and I'm allowed to watch something there, but I'm currently watching a series and... My parents have Prime and they're not going to stop, and with Netflix I don't know how long my sister will be doing it. (Nina)

What is striking about the group of Middle Teens is that the rather strict separation of entertainment and communication media, which still exists among Early Teens, is in the process of dissolving. Social media platforms such as Instagram, but also the application Snapchat, which is also used for communication, are counted as entertainment media. When asked how she relieves boredom, 16-year-old Charlotte, for example, replied 
I use Snapchat most at the moment. That is actually now the thing I really use the most. Yes, that is actually - I'll say it now - not so much to have a real conversation, but rather - I say - yes, on a daily basis, more as "for fun" or as a side factor. (Charlotte)

Consequently, it can be summarized that Middle Teens' access to entertainment media is expanding, while communication and entertainment applications are simultaneously converging.

\subsubsection{Information}

There is a clear change in the acquisition of information between the group of Early Teens and Middle Teens. Information about world events is no longer received passively via the media set of parents or friends. Instead, an awareness is developing that they should also inform themselves independently. 16-year-old Albert even sees this as a personal responsibility: "I always think that it's important for the youth of today to look up news and see what's happening around them, not only in their lives, but in those of the others." However, this is not only due to a personal sense of responsibility, but also to the peer group, where news can also become a topic of conversation, as 15-year-old Jonas says

You also exchange with your friends, like "I heard this and this" and then the other person comes and says, "I heard that" and then you puzzle a bit and talk about it with your friends, that's how you get to know something like that. (Jonas)

Middle Teens continue to follow the news through their parents' media repertoire, but at this stage they also start to add their own selected sources to their repertoire, ultimately leading to a kind of patchwork structure of information sources, composed of both the family's information repertoire and their own sources. In most cases, this results in a mixture of analogue media such as the television and/or the radio, since these are equally accessible to everyone in the household, and online sources, for example news apps on the smartphone or news channels in social networks. Online sources are clearly preferred because they are more up-to-date than print media, are often free of charge, and are easier to tailor to personal interests. As they now also receive their own news sources, Middle Teens are also beginning to look more closely 
at the trustworthiness of information media. Although the group informs itself a lot by means of online sources, it also strongly distrusts them and names public legal news media as serious and valid sources and tends to refer to the media repertoire of the parents. Despite the fact that 16-year-old Moritz, for example, frequently informs himself online and via news apps, he rates Internet sources as less trustworthy overall.

Actually, you can't trust anyone. It's actually pretty bad to trust the Internet. On Wikipedia, for example, anyone can write something. And if someone uploads something and all the news platforms read this, then they upload it too and everyone thinks that it is. In general, you should be careful on the Internet and not believe every website. (Moritz)

Albert, 16, also explicitly points out that he checks news sources he receives via social networks for their truth content, as he considers them less trustworthy.

Another source of news that I use, but I know it's very unorthodox, is Facebook. I like to tell Fake News apart from True news, because I look up the sources and I look it up to see if it's a reliable source, so I don't fall for "Clickbait". (Albert)

Overall, there was a clear change in the pattern of media use between Early Teens and Middle Teens. The fact that information is generally preferably obtained online remains unchanged, but from the Middle Teens onwards, young people begin to receive news not only through the media repertoire provided by the parental home. They develop an individual interest in certain topics and, above all, an initial awareness of the trustworthiness of sources. A certain paradox arises here, since online sources are classified by young people as the least reliable, but they are the most frequently received. The analogue news sources of the parental home are therefore retained as an anchor to distinguish between "true" and "fake news".

\subsubsection{Participation}

One of the biggest changes between Early Teens and Middle Teens takes place in the category of participation. From the Middle Teens onwards, a more concrete and differentiated idea of personality spheres with regard to digital communication emerges for the first time. Since Middle Teens share personal information much more frequently with others via messenger apps or social networks, a negotiation of priva- 
cy management strategies also takes place. A special feature of this group is therefore that communication with peers is clearly differentiated, while communication with the family remains largely unchanged. For the most part, this takes place exclusively face to face or for organizational matters by telephone or via messenger. With the peer group, on the other hand, digital communication is now perceived as a relevant factor in maintaining relationships. 16-year-old Charlotte, for example, formulated a certain necessity to use messenger apps for this purpose.

I have the feeling that you almost have to use messengers. I have friends with whom I used to go to primary school and with whom I'm actually very good friends, but whom I don't see as often in everyday life because of my hobbies, their own hobbies and of course school, and then I think it's almost a must in order to keep in touch, you almost have to have contact via Snapchat or WhatsApp or something. (Charlotte)

Maintaining relationships with friends requires the sharing of personal information. Since in Charlotte's case this can no longer take place face to face for reasons of time or location, other people become digital co-owners of private information and, thus, a confidant and a friend. The proof of trust provided by the shared information about everyday life, special moments etc. nurtures the relationship. In the case of more passive communicating apps like Instagram and Snapchat, this occurs without the need to initiate an additional private conversation on messengers like WhatsApp. This is perceived as a great advantage to maintain relationships:

For example, I'm also in contact with my exchange student via [Snapchat], who I haven't seen for a while now. I just have the feeling that you somehow get the most information about what the other person is doing at the moment and where he or she is based on pictures and the text that you can write about it. So, I think that's actually the reason why I use it the most. (Charlotte)

Another privacy management strategy is the question of whether the personal mobile phone number is shared with others and thus whether contact can be made via messengers such as WhatsApp. The interviews showed that the private mobile phone number tends to be reserved for close friends and family. With fleeting or new acquaintances, Middle Teens tended to build relationships via platforms where the 
mobile number does not have to be given out, as is the case with Snapchat, among others. For example, 15-year-old Mona explained in conversation:

It's always like that when you're on Snapchat anyway, and then they say 'Oh, come on, let me tag you.' Then it's just Snapchat or Instagram. But if you really get on well with the person and have talked a lot, then you're more likely to give them your number. (Mona)

The heavy use of Snapchat in the Middle Teens group could also be explained by the fact that, although it is possible to share information, people only become coowners for a limited time, which fosters a sense of non-commitment and control. This mode of operation suggests the ability to better avoid and control privacy turbulences. How long content is available also plays an important role. For example, because shared content on Instagram remains permanent (unless it is actively deleted), it is shared less by Middle Teens. In this way, the uncontrolled emergence of co-owners is prevented. This was evident in the case of 15-year-old Tamara. When asked why she rarely posts on Instagram, she replied

Because I think that other people who I don't know personally are not that concerned and those with whom I have something to do know that I'm here and there or doing something somewhere. (Tamara)

Information that remains permanent should therefore be something 'special', where the positive self-promotion compensates for the possible emergence of privacy turbulences. For example, 15-year-old Mona answered why she rarely posts on Instagram: "Because I don't have enough pictures that I think are worth uploading." What stays consistent with the Early Teens group, however, is that despite heavier use of digital communication, personal conversations are generally preferred for exchanges or in case of conflicts. This is also emphasized by 16-year-old Charlotte.

Of course, if these are issues that are more important now, so not such banal things, or in everyday life in any case. So right now, when I have an argument with a friend or a more serious topic, it's not something I talk about via WhatsApp. (Charlotte) 
In summary, it is clear that Middle Teens not only communicate digitally to a much greater extent, but also choose very specifically how they communicate and via which platform.

\subsubsection{Media literacy}

A significant difference between Early Teens and Middle Teens lies in the fact that from the middle teen level onwards, youth consciously reflects on their own media use for the first time and also criticizes it in some instances. For the first time, a sense of stress in the face of digital communication was formulated. Screen time in general was called into question, and negative effects evaluated. Thus, already from the middle teen stage, conscious actions are taken to reduce smartphone consumption. 15-yearold Linda reports: "I never had my mobile phone with me during school hours. I even give it away voluntarily because I simply notice that I write better grades." At the same time, online time is considered essential to stay in touch with acquaintances and to follow the daily news. The fear of "missing something" or, in the worst case, not being noticed as a person at all, prevents being unavailable for longer periods of time. 15-year-old Jonas describes it in very drastic terms.

You simply can't do without media these days, not at all. Nothing works anymore, so nowadays you can forget it. You're never up-to-date, you're just nothing and you can just kill yourself, I'll say that now. It's a rough way of putting it, but it feels like that because you just don't get anything anymore [...] Young people don't sit down together or play rummy, they prefer to go online. (Jonas)

In order to 'be somebody', personal information is shared. At the same time, the constant sharing and the demand to be aware of each other leads to pressure mechanisms. During the conversation, some young people had already considered uninstalling social apps in order no longer to be exposed to a constant pressure to react to the constant stream of digital communication from others. 15-year-old Mona commented:

With Snapchat, I've often thought about deleting it because it's so annoying sometimes. I have built up flames with over 20 people and then you're supposed to look at it every morning and that's what I find the only annoying thing about it: when I get a black picture like that every morning with, Good morning, written on it, I think to myself: 'Yes, it's slightly unnecessary'. (Mona) 
The emerging perception of having an online identity, protecting it and negotiating its boundaries is probably the biggest difference between the early and Middle Teens.

\subsection{Late Teens - 17 to 18 years old}

\subsubsection{Entertainment}

Compared to information and participation, the entertainment category shows the fewest changes across the three levels. It is clear, however, that the entertainment media of the parents' generation, such as the television, are moving into the background, or - if at all- content is consumed only together with family members. Late Teens are very independent in their choice of entertainment media. From this stage on, there is usually hardly any control by the parental home. However, the peer group still plays a major role. Series or video games are often consumed together, which means that the interests of the peer group are central in the choice of content. 17-year-old Erich says:

I don't play single player games at all. I only play multi-player games, and then it always depends on what my friends are playing. So, when they're in the mood for a game, for example, if a new game is published. (Erich)

Entertainment media are also merging with other categories, such as with social media platforms or apps that are also used for communication, such as Snapchat. In addition, the categories of entertainment and information are converging, for example when platforms like YouTube are used both for entertainment and to obtain information. Respondent Theresa, 18, explains how she uses YouTube both for entertainment and to prepare for school.

I used to watch a lot of gaming on YouTube, but not so much anymore. But I also sometimes watch knowledge videos, so what I actually watch a lot are um, like tutoring videos for school, for example, a lot of biology. I actually watch a video after almost every biology lesson I have, because there are good channels that explain it really well and then you understand it much better. (Theresa) 
Overall, it is evident that entertainment is both designed for the shared experience and that the choice of media does not necessarily involve a change of platform to satisfy different needs.

\subsubsection{Information}

Late Teens are guided by a broad environment in their choice of information media and adapt their needs according to the media repertoires they come into contact with. The academic environment plays a role in the use of information media in several ways. On the one hand, for example, when the acquisition of factual knowledge is required. Here it becomes apparent that a critical approach to sources that was passed on by teachers at school is also employed to some extent. 18-year-old Amalia tells us about this.

I tried not to use Wikipedia much, because luckily, I had teachers who always told us not to. I actually went to the library a lot for papers and stuff - at first just to be able to say [laughs] in my sources that I used a book but then I realized that it's actually good because you don't always have to be scared that it's wrong because it's actually printed and it's from people you can trust and stuff. (Amalia)

Although online sources are often received, print media will continue to be perceived as more reliable and reputable. However, school not only plays a role in the selection of sources, but also with respect to news on world events. Thus, Late Teens sometimes do not acquire a direct repertoire of information media, but rather inform themselves passively, with the peer group and the academic environment acting as gatekeepers who summarise events relevant to them. Erich, 17, describes it as follows.

When something shocking or headline-grabbing happens? [laughs] Somehow, when something like that happens, I hear about it on social media, it's often posted. But otherwise only through family and friends when we talk about something. Or also school, so in social studies we often talk about some new events. (Erich)

Consequently, targeted information is often no longer necessary for Late Teens to feel satisfactorily informed, as this happens automatically for them via various 
platforms, although this does not necessarily have to be via pure information or news media. 18-year-old Theresa describes it as follows:

You somehow find out about everything via some corner, via Snapchat and then there are always the stories on Instagram or on Snapchat or there are also these stories on Instagram and then, when people talk about something, then something like that always comes out, somehow in between. Yes, it's not that I'm specifically looking for something like that, but you just notice it. (Theresa)

It is also important to be able to consume information in a targeted and individualized way. This can happen on the one hand through the peer group, as they often share an interest in certain topics, or on the other hand by Late Teens actively informing themselves and selecting media that are specifically dedicated to their own interests. Theresa, for example, compares her preferred information medium YouTube with the daily news.

I click on the video and see the title and I click on it because I'm interested, because I want to know, and then you can pull yourself together to look at political knowledge, simply because it interests me, and with the news there's so much that I don't necessarily know whether I'm interested at all. Yes, and in general, the way the videos are designed, they come across as very knowledgeable. (Theresa).

In summary, it can be concluded that Late Teens are independently both actively and rather passively consuming information, relying on the peer group, family or school. They trust information that comes from the social environment in particular.

\subsubsection{Participation}

In the stages of early and Middle Teens, a strong negotiation and orientation phase occurs, in which digital communication platforms of the peer group exert great influence on the individual media use pattern. In the Late Teens, however, a process of emancipation begins, in which they distance themselves again from the trends within the peer group and boundaries are renegotiated. For example, 17-year-old Erich describes his relationship with Snapchat. 
Somehow, I didn't feel like using it anymore. You always had to send something to keep the flames going. And then it was always like "You have to send something now", even though you didn't want to send anything. It was somehow a compulsion to send something, I didn't feel like it anymore (Erich).

Late Teens nevertheless often share moments from their everyday lives and, in turn, follow the clips shared by their friends; at the same time, however, they also reflect very carefully on what content is shared and with whom. This shows very differentiated strategies for privacy management. For example, with people who are counted as friends, the Late Teens often share visually where they are or what they are doing in that moment. One strategy of privacy management is to select exactly those platforms on which personal information is disclosed and to differentiate at this point which people are allowed to gain insight and thus become co-owners. The range, the temporal stability of the information and the degree of direct communication are decisive factors here. 17-year-old Daniel puts it as follows:

If [a contact] is only superficial, I'd say give the Instagram account, because that's also something where you're not in direct contact. And if you already understand each other quite well and are on the same wavelength, then maybe the Snapchat account or the mobile phone number. (Daniel)

This shows that people with whom there is no close contact may gain insight into privacy, but this is done via a platform on which little information is permanently shared, since Instagram or Facebook, for example, are usually reserved for sharing only a few special moments. For example, 17-year-old Julius only uses Snapchat to share insights into his everyday life, because on the Facebook platform, too many people whom he does not want to give a detailed or frequent insight into his life become co-owners.

On Facebook, I reach people I might not even want to reach. And on Snapchat, when I send a picture, I can simply better divide up who I send it to and who I don't [...] Because that also happens quite often, that you have some acquaintances, also on Snapchat, who always send a picture to everyone so that they get as many points as possible, but the last time they talked [to you] was a year ago. (Julius) 
Another interesting feature is that contacts are also maintained not by actively and directly communicating with each other, but by sharing snippets of everyday life, which eliminates the need for direct conversation. Sharing this information strengthens the relationship, because, as with written, non-visual communication, other people become co-owners, which serves as proof of trust. In some cases, this can even replace part of the written communication, as the 18-year-old Theresa reveals in the interview for example:

I also think that Snapchat has brought WhatsApp down a bit, because you don't write 'What are you doing right now?', because you can already see what the person is doing via Snapchat, because if you send each other short pictures all the time, then you can already see what the person is doing. (Theresa)

In summary, it can be said that Late Teens use various digital platforms to maintain contacts and from this stage onwards there is already a very differentiated privacy management strategy, within which a precise distinction is made as to how information is shared and with whom.

\subsubsection{Media literacy}

While Middle Teens were already reflecting on their media consumption and considering limiting certain parts of it, Late Teens were much more likely to show signs of fatigue with regard to digital communication media, as well as a very critical examination and, ultimately, a conscious renunciation of them. However, young people who decided to take this step were more likely to take longer breaks from using the media than to give up using them altogether. Although these breaks are perceived as beneficial, the young people ultimately returned to use and perceived this return as not very positive. This is how 18-year-old Viktoria describes it:

Then I tried not checking Instagram for one and a half to two months and deleted the app. That helped me a lot because I didn't go on my mobile phone so much during the study breaks. That was healthy, I think, and when I logged back in, there were so many people on it. Pictures and stories that didn't interest me at all. (Viktoria) 
Late Teens are starting to question more the content that their friends or acquaintances share on social media platforms such as Instagram. The fact that on these platforms only very rare and selected content that is 'worth' sharing (as was noted among Middle Teens) is deliberately shared is increasingly perceived as negative. This also leads to a reduction or even abandonment of use. 18-year-old Constanze remarked on this:

\begin{abstract}
It was more useful for keeping in touch with people and seeing what was going on in their lives. I find Instagram is only used to present oneself as flawless as possible and that's a cult I don't celebrate and don't want to be part of. Nevertheless, I still look at it every day. (Constanze)
\end{abstract}

These developments even lead to a kind of nostalgic memory of the Early Teens when digital communication media played a rather subordinate role in everyday life and were primarily used to organize personal meetings. Concrete actions are taken in an attempt to restore this status, for example, by reverting to the communication media repertoire used at that time. This is what 17-year-old Eleonore describes.

\begin{abstract}
That was once with two people or so and they said whether we shouldn't try to form a group like that and then just try to leave out all the social media for a while and then rather just call each other like we used to and then just maybe meet like we used to and not just write. (Eleonore)
\end{abstract}

In the participation category, there is a remarkable development from Early Teens to Late Teens. Whereas, in the Early Teens digital communication media were hardly used at all, or were used to maintain contacts, Middle Teens were particularly attracted by the new and made the greatest use of them at this stage, leading ultimately to a kind of digital fatigue among the Late Teens. Their own media consumption is perceived as 'unhealthy' and concrete measures are taken to reduce it, a process the peer group is also involved in, as in Constanze's case. 


\section{DISCUSSION}

By looking at the media repertoire of adolescents as a gradual process, it was possible not only to deal with their respective characteristics in a very differentiated and specific way, but also to trace a development process instead of describing the adolescent media repertoire typologically as a fixed construct. The striking differences that existed between the early, middle and Late Teens levels, especially in the categories of information and participation, show above all that the composition of young people's media repertoire represents a recursive process. Contextual factors such as the social environment and personal needs remain the same across the three stages but continue to develop in their relationship to one another, whereby the media repertoire also changes, adapts and develops. This is illustrated by several examples. For example, the peer group is a decisive factor in the choice of communication media in the Early Teens, so that in the Middle Teens there is a very broad repertoire, from which Late Teens begin to emancipate themselves again and determine for themselves which communication media they want to use, and to what extent. There are always changes in this category, while communication media to communicate with family members, especially parents, remain largely unchanged. At the same time, the category of communication media, at least in the Early Teens, was subject to the strongest regulation by parents, while, for example barely any control by the parents was reported when it came to the choice of entertainment media. The choice of entertainment media was particularly strongly dependent on the peer group. Certain entertainment media, such as video games, were even used only in the company of peers. The entertainment media received proved to be a bonding agent for consolidating social relationships and an important basis for connecting communication and the feeling of belonging, which is why the peer group played an important role in this across all three levels. However, there is also an interaction between personal interests and the individual circle of friends.

The development of information media, on the other hand, resembles a patchwork process in which not only peer groups but also family and the academic environment are important contextual factors. In the early stage of Early Teens especially, the media repertoire of parents is decisive when young people inform themselves about world events and continues to be formative for further developments, even if a process of emancipation also takes place here and young people individually acquire their own sources. However, the media repertoire of parents remains a reliable an- 
chor medium against which the trustworthiness of other sources is measured. A part of the media repertoire in this category could therefore be described as inherited. At this point, however, a limitation of the study should also be mentioned: The homogeneity of the sample as regards the academic background of the interviewees. A large proportion of the interview participants attended a grammar school and were aiming for university entrance qualification. Although the highest level of education of the parents was not established, it can be assumed that the majority of interviewees are situated in a strongly academic environment and that this had a great influence on the appraisal of the information category. Since the interviews showed that in this category in particular the media repertoire of the parents is decisive for the personal use of information media, there is consequently a strong bias. In further studies, a greater diversity of educational background should therefore be aimed for.

As an overriding trend, it also became apparent that young people do not assign media to specific functions but use platforms multifunctionally as they get older. For example, social media such as Instagram or streaming platforms such as YouTube are becoming multifunctional tools that are used for entertainment as well as for information and participation.

In the latter category especially, there were strong differences between Early and Late Teens. What is particularly exciting here is the very reflective differentiation of information sharing that takes place across the three stages. As explained in more detail in the evaluation, throughout adolescence strategies of privacy management develop which go hand in hand with the increased use of digital communication media. However, this can also be interpreted as a dark side, since a feeling of overload and pressure was also formulated as a result of the expanded spectrum of digital communication media. This, in turn, even resulted in a conscious turning away from digital communication media in the Late Teens stage.

\section{CONCLUSION}

One thing is certain: when researching the media repertoire of young people regarding the choice of applications and end devices, it is possible to capture only snapshots at best. Key events like the Covid-19 pandemic, which started after the empirical phase, have without doubt altered the media use patterns of the interviewees. Which social networks or messengers and entertainment media are used in particular is sub- 
ject to rapid change, especially in adolescents. However, the factors that play a role in the development of media use patterns are enduring. The fact that an understanding of digital privacy management already emerges in adolescence is relatively independent of the specific platforms on which it is negotiated. This is because, from the Middle Teens onwards, a negotiation takes place, especially with the aim of reducing the stress that arises from the daily use of digital communication media. In fact, this feeling and especially concrete actions to reduce media consumption emerged only during the evaluation phase of the interviews and were not explicitly asked as part of the guideline. To address this development more specifically, it would be advisable to follow up on this topic in further research. Overall, the study shed light on a number of important trends that would be worth exploring in further research. The convergence of media for entertainment, information and participation clearly shows that approaches that examine specific parts of the media repertoire of young people often miss part of the context. As such, a holistic perspective should be preferred.

Today, the young people interviewed in the study are already young adults today, or Middle Teens rather than Early Teens. Following this development with a longitudinal study would be a good way to test the thesis of the gradual development of media-oriented behaviours. Although this study attempted to bridge the contrast between media-related actions as meaningful practice and media-related actions as need-satisfaction by paying attention to their contextual factors, there are nevertheless limitations due to the purely qualitative approach. For this reason, we suggest that both qualitative methods and a quantitative approach be combined in follow-up research.

\section{REFERENCES}

Choi, H., Park, J., \& Jung, Y. (2018). The role of privacy fatigue in online privacy behaviour. Computers in Human Behaviour, 81, 42-51. https://doi.org/10.1016/j. chb.2017.12.001

Crone, E. A., \& Fuligni, A. J. (2019). Self and others in adolescence. Annual Review of Psychology, 71, 447-469. https://doi.org/10.1146/annurev-psych-010419-050937

De Wolf, R. (2020). Contextualizing how teens manage personal and interpersonal privacy on social media. New Media \& Society, 22 (6), 1058-1075. https://doi. org/10.1177/1461444819876570 
Youth media repertoires: Age ranges, context factors and privacy management

Ecarius J., Köbel N., \& Wahl K. (2011). Was ist Familie? Familie, Erziehung und Sozialisation. VS Verlag für Sozialwissenschaften.

Feierabend, S., Plankenhorn, T., \& Rathgeb, T. (2016). Social Media im Alltag von Kindern und Jugendlichen. Studies in Communication Sciences, 16 (2), 150-162. doi: 10.1016/j.scoms.2016.10.001

Hasebrink, U., \& Domeyer, H. (2012). Media repertoires as patterns of behaviour and as meaningful practices: A multimethod approach to media use in converging media environments. Participations. Journal of Audience and Reception Studies, 9 (2). 757-779.

Hasebrink, U., \& Popp, J. (2006). Media repertoires as a result of selective media use. A conceptual approach to the analysis of patterns of exposure. Communications, 31 (2), 369-387.

Katz, E., Blumler J., G., \& Gurevitch, M. (1974). Utilization of mass communication by the individual. In J. G. Blumler \& E. Katz (Eds.), The uses of mass communications: Current perspectives on gratifications research (pp. 19-32). Sage.

Kim, S. J. (2014). A repertoire approach to cross-platform media use behaviour. New Media \& Society. 18 (3), 1-20. https://doi.org/10.1177/1461444814543162.

Krotz, F. (2019). Neue Theorien entwickeln: Eine Einführung in die Grounded Theory, die Heuristische Sozialforschung und die Ethnographie anhand von Beispielen aus der Kommunikationsforschung (2nd ed.). Herbert von Halem Verlag.

Len-Rìos, M. E., Hughes E. H., McKee, G. L., \& Young, N. H. (2016). Early adolescents as publics: A national survey of teens with social media accounts, their media use preferences, parental mediation, and perceived Internet literacy. Public Relations Review, 42 (1), 101-108. doi: 10.1016/j.pubrev.2015.10.003

Linke, C., \& Schlote, S. (2018). Medienalltag verstehen: Auswertungsstrategien der Grounded Theory und der Heuristischen Sozialforschung für multi-methodische Analysen der Medienkommunikation in alltäglichen Lebenswelten. In A. M. Scheu (Ed.), Auswertung qualitativer Daten: Strategien, Verfahren und Methoden der Interpretation nicht-standardisierter Daten in der Kommunikationswissenschaft (pp. 69-81). Springer VS. 
Madden, M., Lenhart, A., Cortesi, S., Gasser, U., Duggan, M., Smith, A., \& Beaton, M. (2013). Teens, social media, and privacy. Pew Internet \& American Life Project. Retrieved 4/14/21 from http://pewinternet.org/Reports/2013/Teens-SocialMedia-And-Privacy/Summary-of-Findings.aspx

Marwick, E., A., \& boyd, d. (2014). Networked privacy: How teenagers negotiate context in social media. New Media \& Society, 16 (7), 1051-1067. https://doi. org/10.1177/1461444814543995

Misoch, S. (2019). Qualitative Interviews (2nd ed.). De Gruyter.

Müller, K., F. (2018). Theoretisches Kodieren von Interviewmaterial. Medienaneignung mit der Grounded Theory induktiv analysieren. In C. Pentzold, A. Bischof \& N. Heise (Eds.), Praxis Grounded Theory: Theoriegenerierendes empirisches Forschen in medienbezogenen Lebenswelten (pp.149-169). Springer VS.

Nave-Herz, R. (2002). Die Familie im Wandel. In F. Faulbaum \& C. Wolf (Eds.), Gesellschaftliche Entwicklungen im Spiegel der empirischen Sozialforschung (pp. 3957). Springer Link.

Petronio, S. (2013). Brief status report on communication privacy management theory. Journal of Family Communication, 13 (1), 6-14. https://doi.org/10.1080/15 267431.2013.743426

Petronio, S. (2002). Boundaries of privacy: Dialectics of disclosure. University of New York Press.

Rosengren, K. E., Wenner, L. A., \& Palmgreen, P. (1985). Media gratifications research: Current perspectives. Sage.

Rothmund, T., Elson, M., Appel, M., Kneer, J., Pfetsch, J., Schneider, F., \& Zahn, C. (2015). Macht Gewalt in Unterhaltungsmedien aggressiv? Gehirn und Geist. 10/15, Spektrum. Retrieved 14.04.21 from http://www.spektrum.de/mediengewalt

Ryan, A., M. (2001). The peer group as a context for the development of young adolescent motivation and achievement. Child Development, 72 (4), 1135-1150. doi: $10.1111 / 1467-8624.00338$

Schütz, A., \& Luckmann, T. (1979). Strukturen der Lebenswelt. Suhrkamp. 
Smetana, G. J., Campione-Barr, N., \& Metzger, A. (2006). Adolescent development in interpersonal and societal contexts. Annual Review of Psychology, 57, 255-284. https://doi.org/10.1146/annurev.psych.57.102904.190124.

Steinberg, L. (2014). Age of Opportunity: Lessons from the new science on adolescence. Houghton Miflin Harcourt.

Strübing, J. (2014). Grounded Theory. Zur sozialtheoretischen und epistemologischen Fundierung eines pragmatischen Forschungsstils (3rd ed.). Springer VS.

Van Der Velden, M., \& El Emam, K. (2012). Not all my friends need to know: A qualitative study of teenage patients, privacy, and social media. Journal of the American Medical Informatics Association, 20 (1), 16-24. https://doi.org/10.1136/amiajnl-2012-000949

van Kruistum, C. J., Leseman, P. P. M., \& de Haan, M. (2014). Youth Media Lifestyles. Human Communication Research, 40 (4), 508-529. http://dx.doi.org/10.1111/ hcre. 12033

Webster, J. G. (2011). The duality of media: A structurational theory of public attention. Communication Theory 21 (1), 43-66.

Webster, J. G., \& Phalen, P. F. (1997). The mass audience: Rediscovering the dominant model. Mahwah, NJ: L. Erlbaum Associates.

Wonneberger, A., Schoenbach, K., \& van Meurs, L. (2011). Interest in news and politics - or situational determinants? Why people watch the news. Journal of Broadcasting and Electronic Media, 55(3), 325-343. https://doi.org/10.1080/088 38151.2011 .597466

York, C., \& Scholl, R. M. (2015). Youth antecedents to news media consumption: Parent and youth newspaper use, news discussion, and long-term news behavior. Journalism \& Mass Communication Quarterly. 92 (3), 681-699. https://doi. org/10.1177/1077699015588191

Zillmann, D. (2000). Mood management in the context of selective exposure theory. In M. E. Roloff (Ed.), Communication Yearbook, 23 (pp. 103-124). Routledge. 


\section{APPENDIX}

\section{Table 1}

Overview of the respondents quoted

\begin{tabular}{ccl}
\hline Pseudonym & Gender & Age \\
\hline Early Teens & male & \\
Ben & female & 13 years \\
Olga & male & 13 years \\
Manuel & male & 13 years \\
Leonard & female & 13 years \\
Larissa & & 14 years \\
\hline Middle Teens & male & \\
Jonas & female & 15 years \\
Linda & male & 15 years \\
Albert & female & 16 years \\
Charlotte & male & 16 years \\
Moritz & female & 16 years \\
Mona & & 15 years \\
\hline Late Teens & male & 17 years \\
Erich & male & 17 years \\
Daniel & female & 17 years \\
Eleonore & male & 17 years \\
Julius & female & 18 years \\
Amalia & female & 18 years \\
Viktoria & female & 18 years \\
Constanze & &
\end{tabular}


Youth media repertoires: Age ranges, context factors and privacy management

\section{Table 2}

Interview guide

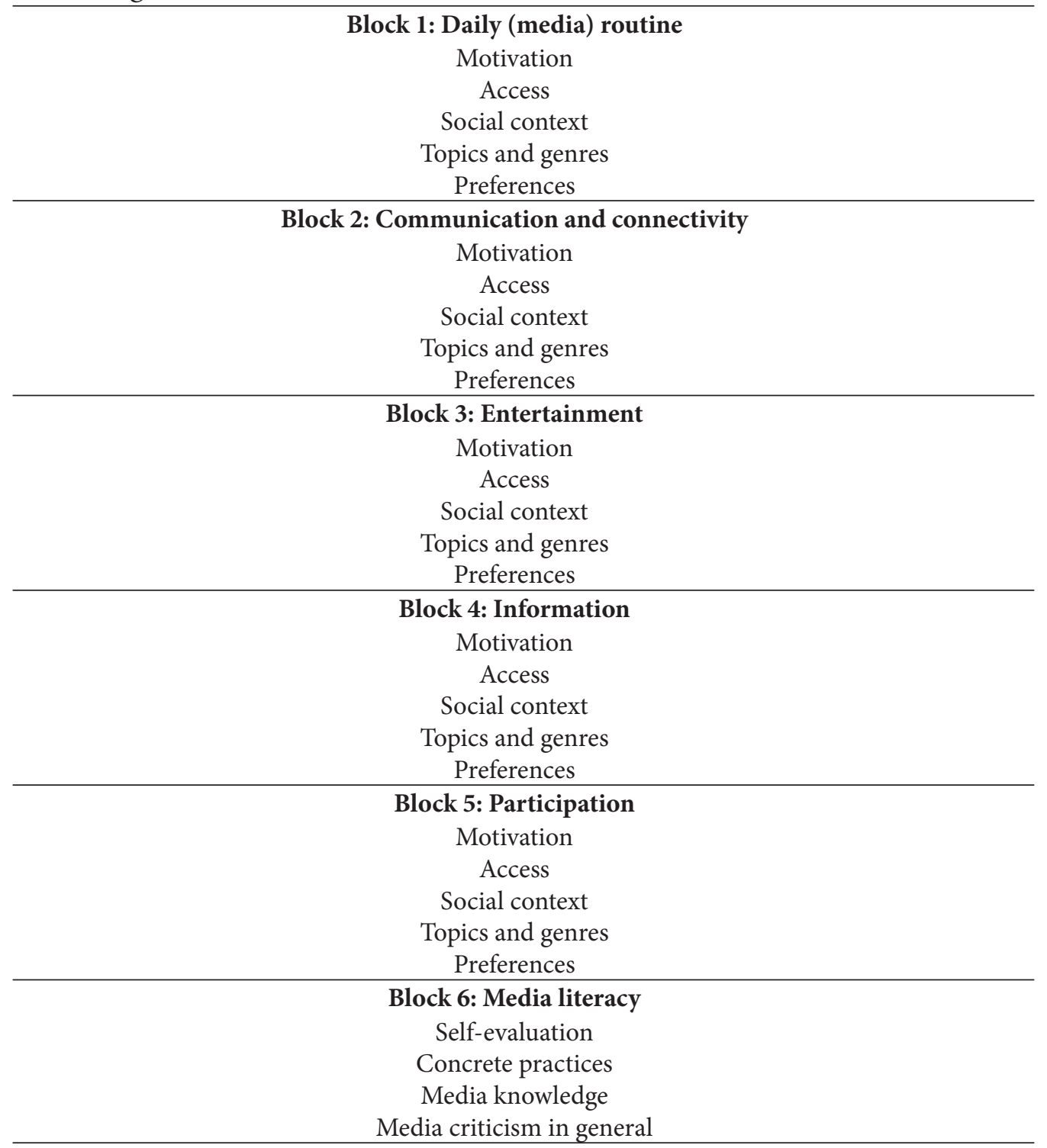




\section{Table 3}

Axial coding categories

\begin{tabular}{|c|c|c|}
\hline Category & Definition & \\
\hline $\mathrm{C} 1$ & Daily routine & $\begin{array}{l}\mathrm{C} 1 \text { includes the integration of media or } \\
\text { media content into daily habits and actions } \\
\text { of individuals as well as specific activities and } \\
\text { their timing. }\end{array}$ \\
\hline $\mathrm{C} 2$ & $\begin{array}{l}\text { Communication and } \\
\text { connectivity }\end{array}$ & $\begin{array}{l}\mathrm{C} 2 \text { describes the use of media devices or } \\
\text { media platforms for communication and } \\
\text { elaborates on the type of communication and } \\
\text { connectivity. }\end{array}$ \\
\hline C3 & Entertainment & $\begin{array}{l}\text { C3 describes the use of media devices or } \\
\text { platforms for entertainment purposes and } \\
\text { elaborates on its content and social context }\end{array}$ \\
\hline $\mathrm{C} 4$ & Information & $\begin{array}{l}\text { C4 refers to the use of media devices or } \\
\text { platforms to seek information for further } \\
\text { education or news search, specifying the type } \\
\text { of content as well as the social context. }\end{array}$ \\
\hline C5 & Participation & $\begin{array}{l}\text { C5 records individual participation on differ- } \\
\text { ent online platforms or offline communities, } \\
\text { specifying the type of participation as well as } \\
\text { its characteristics, for example active/inactive } \\
\text { or public/private. }\end{array}$ \\
\hline C6 & Media literacy & $\begin{array}{l}\text { C6 concretises the individual ability to con- } \\
\text { sciously reflect on and evaluate media-related } \\
\text { actions. }\end{array}$ \\
\hline
\end{tabular}




\section{Table 4}

Theses regarding the development of young people's media repertoire

Thesis 1: The emergence of the media repertoire is a recursive process.

Thesis 2: The choice of entertainment media is strongly and reciprocally influenced by the peer group.

Thesis 3: The development of an information repertoire is a patchwork process of family factors, peer group and the academic environment, in which parts of the media repertoire of the parental home are 'inherited'.

Thesis 4: Media for entertainment, information and participation converge in advancing adolescence.

Thesis 5: The peer group plays a major role in the choice of communication media, which is always renegotiated, whereas with the family, media for communication remain largely unchanged.

Thesis 6: Strategies of privacy management emerge from the development of a broader media repertoire for digital communication,

Thesis 7: As a privacy management strategy, young people are already taking concrete measures to reduce their media consumption. 